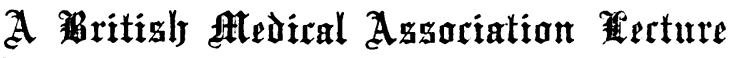

\section{RADIUM THERAPY.}

\section{ROBERT KNOX, M.D.,}

HONORARY RADIOLOGIST, KING'S COLLEGE HOSPITAL; DIRECTOR, RADIOTHELAPEUTIC DEPARTMENT, CANCER HOSPITAL.

The subject on which I have been asked to speak covers so much ground that it will be possible only to deal with broad principles and gire an indication of the vilue of radium in treatment-more particularly in the treatment of malignant aisease, for it is in this field that so much has been expected from the use of radium.

New agent is powers are not at first properly appreciated, must pass through the stages of overestimation, depreciation, and possibly rejection, before their true value is arrived at. When an agent which appears to act upon all structures with which it comes in contact is employed, the difficulties increase proportionately with its effect upon these structures; and the greatest care must be exercised in all attempts to estimate its value. Ilie radio-active bodies belong to this class, and it is very difficult even approximately to estimate their value.

The range of therapentic activity of radiations is an exceedingly wide one, extending from the ultra-violet to the penetrating gaimma rays of radium. The fundamental principle of radiation tlierapeutics is easily understood, if it is realized that the wave length of the radiation is the determining factor. "When the correct ware length for a particular depth has been estimated, it is then merely a matter of time-that, is, duration of the exposure--to produce a particular effect upon the tissues. The effect of radiations is dependent upon the power of absorption the tissues possess for these particular wave lengths, and the absorption of the radiations causes changes in the cells, which may vary in their degree; amongst others chemical changes may result which have a far-reaching effect upon the organism.

In order to obtain effects over a wide range of morbid processes, it is necessary to have at our disposal racliations of all wave lengths, so that any coudition may be treated. In $x$ rays and radium we possess the particular values required. Large quantities of radium may be used with advantage, as, for example, at the Middlesex Hospital, where 5 $\frac{1}{2}$ grams have been used for varying times in the treatment of malignant disease.

Relative Values of X Rays and Radium.

A great deal of unnecessary discussion has taken place on the relative values of $x$ rays and radium rays, the assumption being that these agents act differently ou the tissues. The matter will be more clearly understood if we assume that we are dealing with radiations which have a very wide range of wave length, the gamma ray from radium representing the extreme limit of penetrating power. Given an equal wave length from either agent the effect will be the same. The $x$-ray value has been, up to the present, limited by the inability of the apparatus to generate the high voltage neces. sary to produce $x$ rays equal to the gamma ray from radium. So far it has only been possible to use voltages from 200,000 to 300,000 ; the voltage required to produce $x$ rays equal to the hardest gamma rays is approximately between one and $t w o$ millions. Nevertheless, the voltages of 250,000 give us a very useful radiation, which, if applied in sufficient intensity, may give very good therapeutic results. For example, cancer of the cervix uteri may be influenced by massive doses of $x$ rays administered through several ports of entry. The dose may have to be very prolonged, from five to eight hours at a single treatment. Good effects are claimed for this particular technique. Radium is more applicable to the growth, and gives very brilliant results; these are, however, purely local, and are not permanent. The use of both agents would appear to be a rational procedure. By this method of attack it is possible to obtain the maximura effect from botli agents, the radium acting from a local focus, and spreading autwards to the periphery, while the $r$ rays are insed from the periphery to a central focus point. The tissues are thoroughly saturated and simultaneously attacked from all points. It is possible that in this way peripheral extension of the new growths may be checked.

Superficial lesions are the most favourable for treatment, in so far as they can be kept under continual observation and progress noted; occasionally it is possible to remove a piece of tissue for examination, when clianges in tissue due to the treatment may be noted, and the exact character of the con. dition ascertained. The study of the changes induced in superficial structures gives an accurate indication of the type of case likely to respond to treatment, and also illustrates clearly the probability of influencing deeper morbid conditions; for it will be seen that the simple conditions, such as chronic inflammatory lesions, simple ulcers, naevi, etc., can be beneficially treated with a remarkable accuracy, while those conditions which verge on the malignant-that is, rodent ulcer and epithelioma-are more intractable, the very malignant forms of carcinoma frequently resisting treatment altogether.

Exactly the same sequence is noted in the so.called deep therapy. The effects are, however, much more difficult to obtain on account of the greater difficulty in administering the correct dosagc; more penetrating radiations are required in order to reach the depth of the lesion, wliile the intervening tissues absorb in a diminishing ratio, according to their depth from the surface, the radiations which have to pass through them to reach the tumour. When these difficulties are allowed for it will be secn that the order of response is almost identical with that of the more superficial lesions.

Consideration of the Physical Data of Radium.

Before dealing with the technique and practical application of radium a short referencé to the physics of radium will be useful.

The physics of radium is a most interesting but somewhat difficult subject for the average medical man, who has long ago left behind him what elementary kuowledge he possessed, as a student, of pliysics. For future medical men there can be no doubt that the pliysics side of the curriculum must be.,increased, and it would be well if all practitioners lept closely in touch with this subject throughout their years of practice. A correct appreciation of physical laws will enable them to understand many things which are at present obscure.

It is now known that the $x$ rays are another manifestation of radiant energy, of which light and heat are familiar examples. The $x$ rays resemble light rays in almost every particular, the chief difference being that the $x$ rays have wave lengths about 5,000 times shorter-that is, the $x$ rays are situated far beyond the violet end of the visible spectrum, and may be regarded in a sense as a "treble" form of ultraviclet light. It was this very minuteness of wave length-a distance of the same order as the size of atoms-that de. feated all the earliest attempts to direct and sort out the rays. Just abcut a single octare of light waves is visible to the eye.

\section{Radiux.}

The prominent member of the uranium series of radiosctive elements, belonging to the alkaline earth group of elements. Its parent is ionium, and its disintegration product radium emanation. Radium was discovered in 1898 by M. and Mme. Curie. The discovery was preceded by Becquerel's discovery of radio-activity in 1896.

Radicy Salts.

The word radium, as it is generally used, signifies a radium salt, and in a stricter sense generally up to the present radium bromide $\left(\mathrm{RaBr}_{2} \cdot 2 \mathrm{H}_{2} \mathrm{O}\right)$. Other salts are used, however, so in describing preparations of radium it has become customary, as well as more accurate, to state the radium e!ement content of the salt. Buyers of radium are advised in their own internsts to have the salt certified by the National Physical Laboratory, Teddington.

The salts most commonly used are the sulphate, bromide, and cluloride. The hydrated bromide $\left(\operatorname{RaBr}_{2} \cdot 2 \mathrm{H}_{2} \mathrm{O}\right)$, when pure, contains about 53.6 per cent. of radium element. The pure anhydrous radium bromide (RaBr) contains 58.6 per cent. radium element. The pure sulphate $\left(\mathrm{RaSO}_{4}\right)$ contains 70.2 per cent. radium element and pure radium chloride $\left(\mathrm{RaCl}_{2}\right)$ contains 76.1 per cent. radium element. The chloride and bromide are soluble in water, while the sulphate is insoluble in water and soluble in acids.

Radium emanation has a steady decay period; it falls to half value in about five days; when using the emanation in treatment the decay value has to be taken into account in estimating the exposure.

In whatever manner the radium is used-that is, in tubes, plaques, or in the form of emanation in suitable containers- 
Table I.-Uranium-Radium Family.

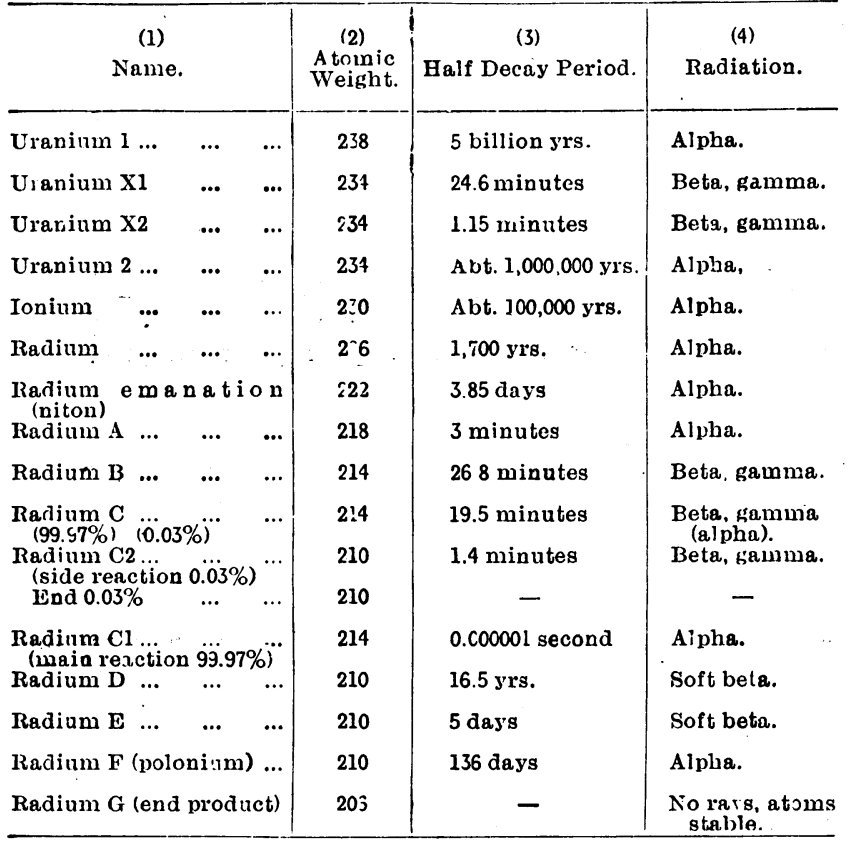

it is found that there are three types of rays given off : alpha, beta, and gamma. The alpha ray is not used to any extent. The beta and gamma rays are most active, and induce changes in the tissucs which are most important from the therapeutic point of view. It is on a correct appreciation of the biological action that successful treatment will depend. 'The point cannot be dealt with fully now, but it is essential that the radiologist be fully conversant with this matter.

Beta rays are negative electrons shot out from the nucleus of the transmitting radium atom with a velocity which in some cases is nearly that of light. Beta rays are more penetrating than alpha rays, the swifter or harder beta rays being half absorbed in almost $1 \mathrm{~mm}$. of soft tissue or $01 \mathrm{~mm}$. of lead or silver. The next equal thickness of these materials will then absorb about 50 per cent. of the remaining ray, so that $10 \mathrm{~mm}$. of tissue, or $1 \mathrm{~mm}$. of lead or silver, absorbs 99.9 per cent. of these hard beta rays. The beta rays from radium $B$ and $C$, in equilibrium with a gram of radium element, produce per hour 4.3 calories of heat. A bundle of parallel beta rays will be deflected from its path by passing through a strong electromagnetic or electrostatic field due to their negative cl:arge, and observations of this deflection in fields of known strength serve to measure the velocity of the beta rays, since the faster the electron travels the less the deviation in a field of given strength. 'The beta rays are closely related to the gamma rays.

Gamma rays are ether vibrations of very short wave lengths (therefore similar to light and $x$ rays); they are caused by the rapid vibrations set up in electrons in the structure of the transmitting element by the electrostatic repulsion between the electron and the escaping high-speed beta ray. The hardest gamma rays from radium $B$ and $C$ are due to beta rays which have initial velocities corre. sponding to differences in potential of from 500,000 to $2,000,000$ volts, and it is probable that the production of $x$ rays of the same short wave length as the gamma rays from radium will require the use of such high potentials.

Recent work, using the molecular crystal structure as a space grating, has led to the determination of the wave lengths of the characteristic $x$ rays and of the softer gamma rays. The wave length of the hard gamma rays is too small to be satisfactorily examined by this method. It is estimated that the wave length of the hard gamma rays lies between 0.01 and 0.001 Angström unit, while the $x$ rays lie in a ranoe between 10 and 0.05 Angström unit, visible light 7.200 to 4,000 Angströin units, ultra-violet in the range 4,000 to 200 Angström units, and the louger radiant lieat waves beyond the red run from $0.06 \mathrm{~mm}$. down to 7,600 Angström units, the Hertzian or wireless waves following on thesc.

Sccondary rays aro formed when thes 3 primary rays impinge upon matter. The alpha rays give rise to. a delta ray. Secondary beta rays are produced in matter by the absorption of the gamma rays.
Filtrations of Radiations from Radium.

For this purpose metal filters are commonly used. These are silver, brass, stee!, lead, gold, platinum, and aluminium; the thickness in millimetres of these substances necessary to absorb 99.9 per cent. of the hard beta rays from radium is as indicated by the figures following:

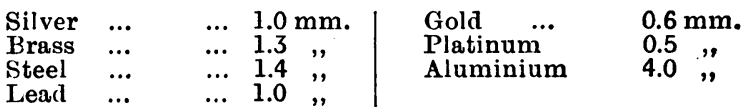

The most useful screens are those of silver and brass.

TABLE II.-Density and Screening Power of Various Materials.

\begin{tabular}{|c|c|c|c|c|c|}
\hline \multicolumn{3}{|c|}{$\underset{\text { Material. }}{\text { Ray Absorbing }}$} & \multirow{2}{*}{$\frac{\substack{\text { Approximate } \\
\text { Density. }}}{10}$} & \multirow{2}{*}{$\begin{array}{c}\text { Thickness of } \\
\begin{array}{c}\text { Absorbing Material } \\
\text { required taabs to b } \\
\text { 50 per Cent. of the } \\
\text { Hard Beta Rays } \\
\text { of Radium. }\end{array} \\
1.00 \mathrm{~mm} .\end{array}$} & \multirow{2}{*}{$\begin{array}{c}\text { Thickness re- } \\
\text { quired to absorb } \\
\text { 99.9 per Cent. of } \\
\text { Hard Beta Ray's } \\
\text { of Radium. }\end{array}$} \\
\hline Water & $\ldots$ & $\ldots$ & & & \\
\hline Gum rubb & & $\ldots$ & 1.0 & $1.00 \mathrm{~mm}$ & $10.00 \mathrm{~mm}$. \\
\hline Soft tissue & & $\ldots$ & 1.0 & $1 . \mathrm{co} \mathrm{mm}$. & $10.00 \mathrm{~mm}$ \\
\hline Bone & $\ldots$ & $\ldots$ & $1.7-2.0$ & $060 \mathrm{~mm}$ & $6 . c 0 \mathrm{~mm}$. \\
\hline Glass & $\ldots$ & ... & 2.6 & $0.40 \mathrm{~mm}$. & $4.00 \mathrm{~mm}$. \\
\hline Aluminiu & $m$ & $\ldots$ & 2.7 & $0.40 \mathrm{~mm}$ & $4.00 \mathrm{~mm}$. \\
\hline Steel... & $\ldots$ & $\ldots$ & 7.7 & $0.14 \mathrm{~mm}$ & $1.40 \mathrm{~mm}$. \\
\hline Brass & $\ldots$ & $\ldots$ & 8.5 & $0.13 \mathrm{~mm}$ & $1.20 \mathrm{~mm}$ \\
\hline Nickel & $\ldots$ & $\ldots$ & 8.7 & $0.13 \mathrm{~mm}$. & $1.30 \mathrm{nım}$. \\
\hline Copp: $\mathbf{r}$ & $\ldots$ & $\ldots$ & 8.9 & $0.13 \mathrm{~mm}$ & $1.30 \mathrm{~mm}$. \\
\hline Silver & $\ldots$ & $\ldots$ & 10.6 & $0.10 \mathrm{~mm}$ & $1.00 \mathrm{~mm}$ \\
\hline Lead... & $\ldots$ & $\ldots$ & 11.3 & $0.10 \mathrm{~mm}$ & $1.00 \mathrm{~mm}$ \\
\hline Gold... & $\ldots$ & $\ldots$ & 19.3 & $0.06 \mathrm{~mm}$ & $0.60 \mathrm{~mm}$ \\
\hline Platinum & $\ldots$ & $\ldots$ & 21.5 & $0.05 \mathrm{~mm}$ & $050 \mathrm{~mm}$ \\
\hline
\end{tabular}

Secondary radiations are given off from metal filters, and these in their turn may have to be filtered because of their injurious action upon the skin; good secondary filters are paper, rubber, gaize, etc.

\section{Action of Radialions upon the Tissues.}

The physiological effects of the radiations from the radioactive substances are attributable to the "photo-electric" effect-that is, the liberation in the structure of the tissue cells of negative electrons. In the case of primary beta rays which are negative electrons their absorption in tissues suffices to start the action. Gamma rays, by their action in evicting secondary beta rays, produce a similar action by the absorption of these secondary beta rays.

When the aim of the exposure is to utilize the beta rays from radium compounds the duration is so relatively short that the gamma ray effect is negligible; but when it is desired to obtain the effect from the more penetrating gamma rays filtration is necessary to cut off the beta rays because of their greater action upon the superficial structure. When dealing with the effects of radiation upon the deeper structures it is necessary to remenber that from a point source the intensity of the radiations diminishes inversely as the square of the distance from the source of the radiations. Consequently from a small radium tube, if the intensity of the radiations at $1 \mathrm{~mm}$. is set at unity, at $2 \mathrm{~mm}$. the intensity is 0.25 , at $3 \mathrm{~mm}$. 0.11 , at $4 \mathrm{~mm}$. 0.06, at $10 \mathrm{~mm}$. 0.01, at $2 \mathrm{~cm} .0 .0025$, al $3 \mathrm{~cm} .0 .0011$.

It is evident from a consideration of these figures that the physiological effect of the gamma rays is limited to distances of 2 to $3 \mathrm{~cm}$. in the treatment of malignant growths, where the dose required to induce the disappearance of the new growth is one which will almost produce a similar effect upon adjacent normal tissue. It also furnishes a scientific proof of the need for thoroughness in the technique of the treatment of malignant disease.

In whichever way the radiations produce these effects 5 . and this is a debatable point on which sound arguments-can be adranced on either side-it is imperative that if the tumorr is to have administered to it an equal dose of radiations throughout its mass, the radium must be distributed at cqual distances, and each tube must have an equal activity. 
RANGE OF ELECTROMAGNETIC WIAVES

UNFFORM VELOCTTY 300000KM PER SECOND

I [ANGSTRÓM UNTT $=10^{-8}$ CENTMEETRE]

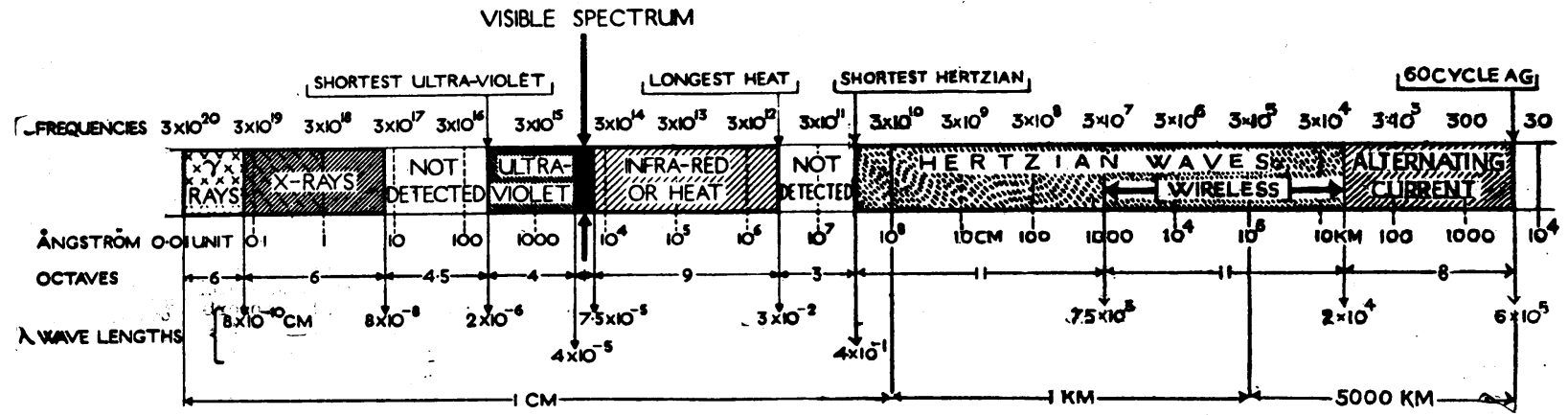

Illustrating diagrammatically the wide range of electromagnetic waves in Nature. (By kind psrmission of Dr. G. W. C. Kaye.)

For this reason it is suggested that the most rational technique is to employ that in which the radium is placed in needles or small tubes of an equal capacity and having filters of equal size. The tubes must be placed at distances not less than $2 \mathrm{~cm}$. apart, and all portions of the tumour should be exposed equally. To obtain this, in many cases of malignant disease a most complete surgical operation will be required, and it is essential that a large quantity of radium should be a vailable. The quantity of radium in each tube need not be very large : $10 \mathrm{mg}$. of element furnishes a fairly active source of radiation; in other cases $25 \mathrm{mg}$. may be used in each tube.

An alternative to the radium in such cases would be to use the penetrating $x$ rays. Combined treatment ensures very thorough radiation of the tumour and its lymplatic field.

The constant endeavour of the $x$-ray instrument designer lhas been to increase the power of the $x$-ray machine and the vacuum tube in order that radiations of shorter and shorter wave lengths, and therefore greater and greater penetration, could be produced. It is now within the range of practical therapeutics to apply wave lengths of radiation, the production of which necessitates the use of voltages up to 300,000 . Great claims are made for the efficiency of the radiations when employed in sufficient intensity and long cxposures in the treatment of malignant diseases. It : will bo increasingly difficult, for technical reasons, to exceed that voltage to any appreciable extent. It is therefore a question whether we should not be content with the use of $x$-ray apparatus working up to 300,000 volts, and rely upon radium for wave lengths beyond those produced at that voltage.

The most important point would be, then, to ensure that a sufficient quantity of radium might be available. For hospital work a well-equipped department would require to have at least 500 milligrams in tubes, and possibly a maximum of 2 grams would be required. Apart from the difficulty of having sufficient radium in the institution, the other argument for centralization of all radiotherapeutic work, especially in deep therapy, is the fact that anaesthetics and surgical operations are often required. Blood examination should be made at intervals, and patients undergoing such heavy treatment must be placed in a hospital or a private nursing institution. The success of radiation therapy depends very largely upon the work of a number of experts acting in nnison. Such combined work can more readily be carried out in a large institution.

The next point to discuss will be the varieties of disease likely to benefit from radium treatment. These may be briefly divided into two groups-non-malignaut and malignant.

\section{Radium Applications in Non-Malignant Cases.}

It is not necessary to discuss cosmetic conditions other than to sound a note of warning in the treatment of the so-called port-wine stains. The greatest care must be taken in these conditions, o'herwise the patient will present a result fully as disfiguring as the original mark.

In angiomas cf all sizes radium is doing work that is simply refiarkable, entirely removing this condition from the surgical field. This is particularly so when dealing with children.

In uterine fioroids, in 40 per cent. of the cases radium or $x$ rays should be the agent of choice, but strict regard must be given to certain contraindications

In uterins haemorrhage radium is almost a specific, but here again due regard must be given to the prevention of certain annoying immediate after-effect, and care must be exercised to ascertain the cause of the haemorrhage. It is well to make it a rule only to treat these cases after consultation with a gynaecologist.

In subacute and chronic leucorrhoea, according to recent reports, radium has proved to be efficient when other methods have failed.

In papilloma of the bladder radium is used after fulguration or operative measures.

In cases of inoperable hypertrophic goitre radium is being employed more and more; in exophthalmic goitre the tendency seems to be in favour of radium as the agent of choice.

The leukaemias offer a large palliative field, and radium seern 3 to control the condition longer than other single methods now employed. Raying the spleen, with transfusion in severe cases, is believed to be the method of choice in many of these conditions. Enlarged thymus in children, according to a recent article by Heublein, is a field in which radium comes to the front as the agent of choice.

Recent reports seem to indicate that radium might cccupy as prominent a place in the treatment of cataract as it now does in the treatment of spring catarrh.

A surgeon seeing the results produced with radium and $x$ rays in tuberculous adenitis will be induced to combine radiation treatment with the surgical if in a number of cases he does not recommend its adoption in the first place.

Radium Applications in Malignant Diseases.

At the present time radium is cousidered the agent of choice in slin cancer when operation has been decided against. Epithelioma, however, being difficult to control, yields ouly palliative results.

Cancer of the lip, when spriuging from the skin surface, is occasionally treated by radium. Springing from the mucous membrane (and very early) it is treated with surgery and radium, with $x$ rays over the glands of the neck and chest. In advanced cases radium and $x$ rays are used over the lesion and glands, including the glands of the chest.

Cancer of the lingual and buccal mucous membrane is treated with radium and fulguration. No sharp-cutting instrument should be used in this region. Salvarsan may be administered as a routiue agent in these cases, giving the salvarsan at the height of the radium reaction. 'This is useful because it is possible to get secondary effects from the combination.

Treatment of malignant disease of the antrum should be operative plus radium. Metastasis does not occur so early in these cases, but the glands should be rayed as a routine measure.

Cancer of the oesophagus is a radium case-with perhap surgery-if in the very early stage. Radium is the best palliative agent in advanced cases, but must be used with care, because of the effect of the ray's on the adjoining tissucs. Very lenetrating $x$ rays may be used from the skin surface.

Cancer of the stomach and intestinal tract is treated surgicaliy, followed, if possible, by radiation. The mechanical difficuities in placing radium in the stomach have not been overcome.

Early caucer of the breast is considered surgical, and radium has rendered seemingly inoperable cases operable. Only in inoperable and advauced cases is radium alone employed, and theu for its palliative effect. Post-operative radiat.on treatment is recommended in all cases of cancer. The best time for prophrlactic treatment is a question that must be decicled for the individual

Cincer of the rectum is a condition not treated satisfactorily from any stantpoint. If it is inoperable, it should be treated by radium and $x$ rays.- Colotomy should be performed $t$ ' prevent irritation to the parts. Rajiations should be applied from all avaiiable aspects.

Cancer of the prostate should be removed (if exrly) and radinm tubes and needles buried at the time of operation. If inoperable, it may be treated by the use of radium needles via the perineum, or the cross-fire-method via rectum and urethra.

In cancer of the bladder radium will ba ntefut, and a suprapubio - operation is done in order to facilitate the placins of the radium and to provide for good drainage. 
Early cancer of the fundus uteri is a surgical condition if the patient is in \& condition to stand a radical operation; otherwise it is a case for radium, and no case, however severe, should be denied the palliative action of radium.

Much of the work which las been done in tlie past has been experimental and empirical. The technique has been extremely crude, and often left in the hands of men who from their lack of skill and training have not been able to use the radium to the best advantage. But haphazard methods have no place in present-day technique. Take, for example, cancer of the cervix ateri. 'The patient must be thoroughly prepared as for operation. 'The gynaecologist is the man best fitted to deal with these very difficult cases. Small quantities of radium or emanations from radium in metal tubes are used. The needle already described is most suitable for this class of work. A tube may be introduced into the cervical canal; around this small needles are inserted into the growth in positions where the greatest activity is required and can be obtained. Close apposition of the tubes to the active edges of the growth will ensure the best results. As many as twelve needies may be inserted into a growth. The cervix with the radium tube and needles is next carefully packed around with gauze, and the vaginal walls are protected (as far as that is possible) by being pushed as far a way from the radium as possible. The vagina is next carefully packed and the requisite exposure given. At the end of the time arranged the radium is removed. It may be necessary to give the patient morphine or other sedatives during the exposure. At the eud of about ten days the patient is inspected and another exposure given. Then at the end of three weeks a further exposure is made. After these three exposures the patient is kept under observation.

In a short time after the last exposure the improvement sets in, and it is no exaggeration to say that in a number of cases the immediate results of radium treatment are very remarkable. The local tumour disappears and leaves a firn pliable scar. The distressing symptoms clear up and for a time the patient returns to normal health.

In these cases a combination of radium and $x$ rays is preferred, the latter being applied from many ports of entry around the pelvis. With the possibility of using the more penetrating $x$ rays, of which so much has been heard lately, the prospect of helping the sufferer is greatly improved. With a skilful application of radium followed by largc doses of $x$ rays, we are almost certain to get vastly improveci results. I am trying both methods singly and coinbined, and at present it is not possible to say which will be the morc reliable method to employ in the future.

Cancer of the rectum is oue of the disappointments of radium therapy; it is possible that the unfavourable results which have followed upon applications are in part due to the faulty technique. The fixation of the tube of radium is not an easy matter; great skill is required to get it into a position where it will exercise a maximum effect. It is suggested that if the growth could be brought into view by dilating the rectal canal, radium needles could be buried in the mass. In this way the irritation of the rectal mucosa would be to a large extent aroided. Long exposures would then be possible. A large number of small needles could be introduced at regular intervals of space in order to get a uniform irradiation. The aim of the treatment is to induce throughout the tumour a degrce of reaction which will result in the absorption of the tumour mass. How this is brought about is not clearly understood, but it is quite clear that if a uniform irradiation is obtained the probability of fafourably influencing the grow th is greater.

A distinguished physician, who ought to have been better informed, is reportcd to have stated that radium had proved to be a failure, and that surgeous were giving up its use and turning to penetrating $x$ rays in the treatment of malignant disease. This is not true at all, though it may have a semblance of truth in it, because so many disappointing results have followed the use of radium in quite unsuitable and hopeless cases. The failure of radium in those cases is not surprising; and need it be pointed out that radium merely follows upon failure of all other methods of treat. ment which have no doubt been tried in the cases sent for radium treatment?

Against this statement may be advanced the conclusions of an experienced observer, Professor Fraukl of Vienna, who recently lectured in Dublin on the subject of $x$ rays and radium. An abstract of his paper was published in the Lancet of December 3rd, 1921, p. 1176:
Professor Frankl pointed out that radium had a limited area of action not exeeeding $4 \mathrm{~cm}$., and that its effectiveness decreased in ratio to the distanee, so that the peripheral portions of a tumour might receive a dose inadeguate to destroy but sufficient to stimuJate the caucer cells. All the cells of the body were, he said, sensitive to $x$ raysor radium, but cancer cells and the specific cells of the ovary more sensitive than others, so that it was possible to destroy tumour cells and tle follicles of the ovary without harming the surrounding tissues, Some gynaecologists had, perhaps, expected too much from rays and radium in the treatment of cancer of the neck of the uterus; there was no excuse for abandoning the knife, aird a combination of the two methods promised to give better results than either alone; it was important to subject cases operated to subsequent treatment by rays. It was also true that in a small percentage of cases treatment by rays might render an inoperable case operable, or even bring about cure. In Fraukl's clinic, of 42 cases of inoperable cancer of the cervix seven had been cured, and 58 per cent. of the cases subjected to ray treatment subsequent to operation remained well for a period of five years. In uterine haenorrhage due to the presence of myomata or unconnected with obvious signs of disease the rays acted upon the follicular elements of the ovary, and by destrofytig them brought about a cessation of ovarian secrettion and so producet amerorrhoea. It had been suggested that small doses might stimulate the follicular epithelium of the ovary and so cure obstinate amenorrhoea.

I am in agreement with Professor Frankt in practically all that he says in regard to radium and cancer. The probability is that in tine we shall arrice at a correct estimate of the value of radiations in treatment. The five ycars given by Professor Frankl as the longest time up to the present he has patients in good health after $x$-ray treatment is not long enough on which to base values. I could quote a large number of cases of malignant disease who have had opera. tions and $x$-ray treatment who are at present quite well. A number of cases in which recurrence has shown itself within the five years period have clcared up and remain well. On the other hand, it is just at the five years limait that $I$ would look out for manifestations of dcep-seated secondary deposits, and I would place the critical period upon which statistics may be based, which would be of value, between five and ten years. It is between these times that the end stages of malignancy will show themselves. I mean particularly in reference to carcinoma, for I believe that sarcomata have a much shorter latent period between the discovery and the removal of the primary growth and the deep-seated recurrence.

If and when we can produce statistics, either operative or radiotherapeutical, which clcarly show a good percentage of patients alive and well ten years or longer after operation or treatment by radiation, it will bo possible to consider tho advisability of making statements of curatire work in caucer.

It has been my fate to watch a large number of cases of cancer in all parts of the body progress towards the end stages of the malady. 'These stages are not pleasant ones to contemplate, and they do not encourage one to become optimistic regarding the treatment of malignant disease. 'True, one sces an occasional brilliant result, and encouragement springs from the sight, but on the whole the results are not good. In a fairly large percentage of cases of carcinoma of the mamma the end condition is one of mediastinal in. volvement: that is a hopeless condition to deal with. Radio. therapeutic measures may relieve, but they never cure. The last of the involvements is the occurrence of bone metastases. These are much more common than is suspected. 'They are often overlooked, ercn in the post-mortem room. Radio. graphy has been helpful in discovering these changes in bone. Bone carcinomatosis is more common than we know. It is probably the end mauifestation of the cancer process, and it may be localized or very general in its distribution. Involvement of bone may occur within five years of the primary lesion, but in my experience it does not of ten become evident before the ficth year, and it may appear at a much later date. From the point of view of ray therapy it is a most hopeless condition. The spread of the disease is so extensive that no amount of radiation can possibly influence it for good, though temporary improvement may follow upon thorough radiation. Nor is it likely that ray therapy can prevent the spread to the osseous system unless the primary dosage can be sufficiently large to clear up the primary growth, and any possible infiltration throngh the lymphatics. It is quite clear that at present we are not giving anything like dosage of such quantity and quality as to influence such wide areas. I therefore plead for the extensive use of radiations from what. ever source available, and I hold that in radium we have an agent which helps towards the attainment of cures, since it carries a source of $5 \in$ ry penetrating radiation into the regions 
where it is most needed, and in which in a number of cases it is not possible to get the equivalent dose of $x$ rays delivered. It is well to use large quantities of radiations as early as possible, and to give a sufficient number of exposures at intervals over a period of, say, two months, and then keep the patient under observation for as long as possible. Watch carefully for evidence of recurrence; when this occurs treat it in the eame way as a primary growth would be dealt with.

In adrocating the use of radium by the surgeon in his operative work, it is clear that two chief points must be realized. He must have a sufficient supply of radium in suitable applicators, and he should know something of the physical properties and action of radium. The principal fields for its use in the hands of the surgeon will be in two types of case:

1. 'The operable case of cancer, where the whole of the tumour can be removed. Ridium is used in this class at the close of the operation as a prophylactic measure. $\mathrm{Mr}$. Sampson Handley is a strong advocate of this method, and he further insists on post-opcrative ray treatment, the com. bination giving the patient the best possible chance of a complete recovery.

2. The inoperable case, in which an operation for the use of the radium is justifiable. In this type of case a large field exists, for the majority of surgically inoperable cases will lrave to be considered from this point of view. The field is a large one, embracing as it does a variety of forms of tumour, and an equally large variety of situations.

It is evident from a consideration of the facts submitted that the possibilities of radium in the treatment of disease have not been nearly exhausted; in fact, up to the present the technique has been more or less experimental. The ex perience of recent years brings forth two dominant facts. 'The potency of radium is now acknowledged by all com. petent workers; it is a most valuable adjunct to the surgeon and the $x$-ray therapist. Indispensable to botb, it is clear that a great future lies before it. To ulilize radium to the utmost it is imperative that much larger quantities must be used than has been customary. Instead of talking in milligrams it will be necessary to think in grams, and to devise techuique which will make it possible to use with safety much larger quantities. 'The larger the quantity used the shorter will be the exposure. This in itself will be an important step, particularly in regions in which the applicrtions are not well tolerated, such as the mouth, pharyux, oesopliagus, rectum, bladder, etc.

The second important point is concerned with the technique of the application. In order to obtain the maximum effect the radium must be accurately applied. The surgeon must be prepared to perform operations for the inscrtion of the radium. In internal regions an exploratory operation may be required to locate accurately the tumour and to place the tubes in position. 'Take, for example, a localized tumour of the pyloric end of the stomach which is incperable. Is it not possible to anchor the tumour in the operation wound insert a number of small tubes into the tumour, allow a few lours for the exposure (and with large quantities of radium used this could be limited to a comparatively short period), remove the radium tubes, and close the wound? Such measures may appcar to be extreme, but is it not a desperate condition which is being dealt with? Surely it is sound practice to give the patient the chance of even a forlorn hope.

The question of radiations versus operation must now be discussed. In all cases, with perhaps one or two exceptions, there can be no doubt that the operative should be the first choicc. In all cases where possible radium should be nsed at the operation, placing it in positions which are likely to contain residual cells. It is surely more logical to endeavour to clieck at the outset any possible residues than to await their development.

The radium exposures should be followed up by thorough $x$-ray treatment. The aim of radium and $x$-ray treatment should be to administer doses of great iutensity in the hope that changes may be brouglit about in the tissues which will lead to the disappearance of any cancer cells.

THE Mayor of Detroit has announced a grant of $1,000,000$ dollars for the purpose of consolidating the Children's Free Hospital and the Michigan Hospital at Framington, to provide additional facilities for the treatment of crippled children in Michigan. Additional contributions to the amount of $5,000,000$ dollars will be made as money is needed for the development of the joint hospital.
THE DIAGNOS'TIC VALUE OF LUMBAR PUNCTURE IN CEREBRAL AND SPINAL HAEMORRHAGES.

BY

WILFRED HARRIS, M.D., F.R.C.P.,

PHYSICIAN FOR DISEASES OF THE NERVOUS SYSTEM, ST. MARY'S

HOSPITAL, $\triangle N D$ TO THE HOSPITAL FOR EPILEPSY AND PaRALYSIS, MAIDA VALE.

For some few years $I$ have realized in increasing degree the extreme diagnostic value of blood mixed with the cerebrospinal fluid remored by lumbar puncture. It is, of course, to be assumed that the lunibar puncture has been cleauly periormed without any great difficulty or prolonged search. ing, as if that happens local haemorrhage due to the pro. longed manipulation of the needle may reach the cerebro-spinal fluid. The blood in such an event is liable to clot easily and is not intimately mixed with the fluid, unless the attempt is renewed on the following or subsequent day, by which time the blood and fluid will be intimately mixed. With this exception, the finding by lumbar puncture of free blood intimately mixed with the cerebro-spinal fluid is a practically certain and invaluable method of rapid differential diagnosis of haemorrhage occurring into the central nervous system, thus distinguishing at once between.apoplexy due to haemorrhage and other causes of cerebral confusion and coma-such as embolism, thrombosis, uraemia, encephalitis, tumour, diabetic coma, epilepsy and general paralysis, disseminated sclerosis, heat-strolse, hysteria, and so on. The one other condition in which blood or its derivative pigments is con. stantly found in the cerebro-spinal flaid is severe concussion with laceration of the brain, and fractured base. '1liere!ore in these two diseases of haemorrhage-either spontaneous, as in apoplexy, or traumatic, due to severe injury-lumbar puncture gives us at once a certain and invariable deciding indication as to whether the lesion is one of haemorihago within the cranial cavity or not. An examination of the chief textbooks on diseases of the nerrous system shows an almost uniform absence of reference to lumbar puncture in the differential diagnosis of apoplexies, though in one or two books devoted to diagnosis the point is mentioned, but not stressed sufficiently.

During the last week $I$ have seen in consultation five cases of acute cerebral apoplexy; in which lumbar puncture showed the cerebro-spinal fluid to be intimately mixed with and opaque with blood. In only tivo of these cases liad cerebral haemorrhage been suggested as the cause of the mental confusion or coma before I saw the patient, uraemia having becn diagnosed in two of tie cases, and encephalitis lethargica in the other.

The listory of the latter case is instructive, inasmuch as the patient lived for fifteen days after the rupture of a small aneurysm on one anterior cerebral artery.

\section{CASE I.}

Miss M., aged 44, had not been feeling well, and had a fainting attack in a 'Turkish bath on March 3rd, but quite recovered. On March 8th she partook of tinned salmon at supper, and was taken acutely ill shortly afterwards with recurrent vomiting and diarrhoea, though other members of the fanily, who had eaten of the same dish, were unaffected. As soon as the sickness began she felt a "flush of bloo:l to the head,"and a sensation of s'eapiness, but was quite conscions, though semi-collapjed when se zu by Dr. Eric Pritchard of Hampstead at 1.30 a.m. The vomiting did not recur, and néxt evening she felt stiffness at tlie baek of the veck and the flushing sensation; being drowsy but able to talk. Even on the third day, during intervals of periols of drowsiness, she would get up fiom the sofa and attend to business, witing cheques and letters, and sos pertectly rationa business, wring cheques and hetters, and was periectly rational, tions. Dr. P'ritchard considered the cass to be one of encephalitis lethargica, and a neurologist w! so sa her with him on the fifth. day confirmed this diagnosis, although he par. lumbar puncture and found the cerebro-spiual fluid y mixed with blood, showing changes in colour and general appearance compatible with a history of four dass in age. I saw her on the eighth day, as during that day she rapidiy became worse, being comatose, with flaccid left hemiplegia, and slight rigidity and muscular twitchings on the right side. 'The case appeared to me as one of undoubted ingravescent cerebral haemorrhage, confirmed by the free blood found in the cerebro-spinal fluid, as I have never seen the slightest trace of blood in the fluid in cases of encephalitis lethargica. Her state made it seem pra. bable that she could not live more than a day or two, yet she lingered another week, with total flaccid paralysis, dying on March 23rd, fifteen days after the initial symptoms of the cerebral haemorrhage. Dr. Spilsbury made a post-mortem examination for Dr. Pritchard and found a ruptured aneurysm, the size of a pea, on the left anterior cerebral artery, one-third of an inch from its 